\title{
The Influence of Experiental Learning Model Assisted Experiment on Material Electrolyte and Non-electrolyte Solutions toward the Learning Outcome of Students Class X MIA at SMA Negeri 3 Palu
}

\author{
*Yonathan Banua, Sri Mulyani Sabang \& Vanny M. A. Tiwow \\ Pendidikan Kimia/FKIP - Universitas Tadulako, Palu - Indonesia 94119 \\ Received 03 December 2019, Revised 08 January 2019, Accepted 14 February 2019 \\ doi: 10.22487/j24775185.2020.v9.i1.pp1-6
}

\begin{abstract}
This research focused on the influence of Experiential Learning Model Assisted Experiment on material electrolyte and non-electrolyte solutions toward the learning result of science students class X MIA at SMA Negeri 3 Palu. This research used quasi experimental with a control group research design using pre-test and post-test. The population was all of c science students class X MIA at at SMA Negeri 3 Palu registered in 2016/2017 academic year. The purposive sampling was used in choosing the sample. The sample in this research was the students of experiment class $(n=32)$ and control class $(n=32)$. The statistic data used one-party test-t test with prerequisite test: normality and homogeneity test. Based on the result of hypothesis testing, it showed that $t_{\text {counted }}>t_{1}-\alpha\left(t_{\text {counted }}=\right.$ 3.35 and $\left.t_{\text {table }}=1.67\right)$ with the level of significance $a=0.05$ and degree of freedom 61 , as the result $H_{0}$ was rejected and $H_{1}$ was accepted, means there was a significant difference between experimental group and control group. Therefore it can be concluded that there was an influence of experiential learning model assisted experiments on material electrolyte and nonelectrolyte solutions toward the learning result of chemistry students X MIA at SMA Negeri 3 Palu.
\end{abstract}

Keywords: Experiential learning, experiment, students learning result, electrolyte and nonelectrolyte solutions

\section{Pendahuluan}

Pendidikan adalah investasi sumber daya manusia jangka panjang yang mempunyai nilai strategis bagi kelangsungan peradaban manusia di dunia (Kunandar, 2007). Pendidikan memegang peranan penting dalam pengembangan sumber daya manusia yang lebih bermutu. Keberhasilan proses pendidikan di tentukan oleh kualitas pendidikan itu sendiri. Pendidikan yang berkualitas akan mempercepat tercapainya keberhasilan suatu proses pendidikan (Dewi dkk., 2013). Oleh karena itu pembaharuan pendidikan harus selalu dilakukan untuk meningkatkan kualitas pendidikan suatu bangsa (Syaodih, 2010).

Terdapat tiga komponen penting yang perlu disoroti dalam pembaharuan pendidikan yaitu pembaharuan kurikulum, peningkatan kualitas pembelajaran, dan efektifitas metode pembelajaran (Isjoni, 2009). Proses pembelajaran merupakan suatu proses yang dibangun oleh guru untuk mengembangkan kemampuan berpikir siswa, serta meningkatkan kemampuan mengkonstruksi pengetahuan baru sebagai upaya untuk menguasai konsep materi pelajaran (Sagala, 2010). Melalui proses pembelajaran guru dituntut untuk mampu membimbing dan memfasilitasi siswa agar mereka dapat memahami kemampuan yang mereka miliki, untuk selanjutnya guru memberikan motivasi agar siswa terdorong untuk belajar sebaik mungkin untuk mewujudkan keberhasilan berdasarkan kemampuan yang mereka miliki (Aunurrahman, 2009).

Siswa seringkali mengalami kesulitan dalam proses pemahamannya sehingga berdampak pada perolehan hasil belajar yang tidak maksimal (Aisha \& Nurhayati, 2013). Menurut Arifin (2009) kesulitan siswa dalam mempelajari ilmu kimia dapat bersumber pada kesulitan dalam memahami istilah dan kesulitan dalam memahami konsep kimia. Keadaan yang demikian diperparah dengan penggunaan model pembelajaran yang cenderung bersifat informatif (Lestari, 2014). Pembelajaran yang cenderung informatif dan searah kurang melibatkan siswa, karena guru memberikan atau menyampaikan informasi atau ide dan siswa dengan pasif menerimanya. Pembelajaran seperti ini membuat siswa tidak terlibat aktif dalam proses pembelajaran, tidak diberi kesempatan untuk membangun pengetahuan mereka sendiri, serta tidak berani mengungkapkan pendapat atau gagasannya sehingga berpengaruh pada hasil belajar siswa (Sari, 2012).

\footnotetext{
*Correspondence:

Yonathan Banua

e-mail: yonathanbanua@gmail.com

(c) 2020 the Author(s) retain the copyright of this article. This article is published under the terms of the Creative Commons Attribution License 4.0, which permits unrestricted non-commercial use, distribution, and reproduction in any medium, provided the original work is properly cited.
} 
Berdasarkan permasalahan tersebut, upaya memperbaiki proses pembelajaran diperlukan model pembelajaran yang sesuai dengan kondisi pembelajaran (Uno, 2009). Penggunaan model pembelajaran yang tepat dapat mendorong terjadinya peningkatan hasil belajar (Fajri, 2012). Model pembelajaran yang dapat meningkatkan hasil belajar yaitu model pembelajaran berdasarkan pengalamannya secara langsung. Dengan menggunakan pengalaman, siswa sedikit demi sedikit dapat mengembangkan kemampuannya untuk memahami konsep-konsep abstrak serta memanipulasi simbol-simbol, berpikir logis, dan melakukan generalisasi. Pengalaman konkret akan sangat efektif dalam membantu proses belajar. Bruner (2005) menyatakan bahwa ketika siswa dilibatkan dalam kegiatan pengalaman konkret, maka keterampilan berpikir kritis dapat dikembangkan sehingga hasil belajar akan meningkat (Gonen \& Ozek, 2005).

Model experiential learning berbantuan eksperimen merupakan model pembelajaran melalui pengalaman menggunakan metode eksperimen. Pengalaman yang akan membangun pemahaman dan keterampilan siswa dalam menciptakan pengetahuan melalui kombinasi antara mendapatkan pengalaman dan mentranformasi pengalaman. Model experiential learning berbasis pada paradigma konstruktivisme. Model experiential learning terdiri dari empat tahapan, yaitu concrete experience, reflection observation, abstract conceptualization, dan active experimentation (Kolb \& Kolb, 2005). Model pembelajaran ini menekankan pada proses pengkontruksian pengetahuan melalui transformasi pengalaman (Sharlanova, 2004).

Tulisan ini dimaksudkan untuk mendeskripsikan tentang pengaruh model experiential learning berbantuan eksperimen pada materi larutan elektrolit dan nonelektrolit terhadap hasil belajar kimia siswa kelas X MIA SMAN 3 Palu.

\section{Metode}

Desain peneitian ini yakni berdasarkan desain dengan kelompok kontrol menggunakan prates dan pascates (randomized control group pretest-pascatest design), Populasi dalam penelitian ini yaitu semua siswa kelas X MIA di SMA Negeri 3 Palu yang terdaftar pada tahun ajaran 2016/2017 sebanyak 256 siswa. Sampel dalam penelitian ini yaitu siswa kelas X MIA 1 yang berjumlah 32 orang, dan siswa kelas X MIA 2 yang berjumlah 32 orang. Teknik pengambilan sampel dengan cara purposive sampling. Teknik sampling ini digunakan untuk menentukan sampel berdasarkan pertimbanganpertimbangan tertentu misalnya tingkat kemampuan siswa yang hampir sama serta sarana dan fasilitas belajar yang sama.

Penelitian ini ditempuh dalam tiga tahap yaitu tahap persiapan, tahap pelaksanaan dan tahap akhir yang ditunjukkan di bawah ini:

\section{Tahap Persiapan}

Tahap persiapan yang dilakukan meliputi observasi lokasi penelitian. Peneliti melakukan observasi dilokasi penelitian dan berkonsultasi dengan guru mata pelajaran kimia kelas X MIA SMAN 3 Palu. Berdasarkan hasil wawancara peneliti memperoleh informasi awal mengenai kendala-kendala yang dihadapi selama kegiatan belajar mengajar, model dan metode pembelajaran yang digunakan, dan hasil belajar siswa. Kemudian menentukan populasi dan sampel penelitian. Merancang perangkat pembelajaran berupa rencana pelaksanaan pembelajaran (RPP) dan lembar kerja siswa (LKS) untuk kelas kontrol dan kelas eksperimen. Kemudian melakukan validitas tes. Validitas tes ini bertujuan untuk mendapatkan soal yang valid agar dapat dijadikan instrumen tes yang nantinya digunakan pada pretes dan postes pada kelas kontrol dan kelas eksperimen.

\section{Tahap Pelaksanaan}

Tahap pelaksanaan yang dilakukan meliputi pemberian pretest pada kelas eksperimen dan kelas kontrol untuk mengetahui kemampuan awal siswa terhadap pemahaman konsep yang disesuaikan dengan materi yang diajarkan. Menerapkan pembelajaran experiential learning berbantuan eksperimen pada kelas eksperimen. Sedangkan untuk kelas kontrol digunakan model pembelajaran konvensional dengan metode diskusi dan ceramah. Memberikan posttest pada kelas eksperimen dan kelas kontrol untuk mengetahui hasil belajar setelah mendapatkan perlakuan.

\section{Tahap Akbir}

Kegiatan yang dilakukan pada tahap akhir yaitu pengolahan, dan pelaporan data hasil penelitian. Hasil analisa data akan digunakan untuk menyimpulkan hasil penelitian.

\section{Instrumen Penelitian}

Hasil belajar siswa disusun dengan maksud untuk memperoleh informasi data hasil belajar siswa setelah proses belajar mengajar, sehingga melalui data hasil belajar tersebut dapat diketahui ada tidaknya pengaruh hasil belajar siswa menggunakan model experiential learning berbantuan eksperimen dengan model konvensional menggunakan metode diskusi dan ceramah pada materi larutan elektrolit dan nonelektrolit.

Uji hipotesis statistik pada penelitian ini menggunakan uji-t satu pihak (kanan). Tujuan dari uji ini untuk membedahkan hasil belajar menggunakan model experiential learning berbantuan eksperimen dengan model konvensional menggunakan metode ceramah dan diskusi pada materi larutan elektrolit dan nonelektrolit. Hipotesis statistiknya adalah:

$\mathrm{H}_{0}$ : Tidak terdapat perbedaan model experiential learning berbantuan eksperimen terhadap hasil belajar siswa.

$\mathrm{H}_{\mathrm{a}}$ : Ada perbedaan model experiential learning berbantuan eksperimen terhadap hasil belajar siswa. 
Hipotesis matematisnya adalah:

$\mathrm{H}_{0}: \mu_{1} \leq \mu_{2}$ dan $\mathrm{H}_{\mathrm{a}}: \mu_{1}>\mu_{2}$

dimana :

$\mu_{1}=$ rata-rata hasil belajar siswa menggunakan model eksperiential learning berbantuan eksperimen; $\mu_{2}=$ rata-rata hasil belajar siswa menggunakan model konvensional dengan metode diskusi dan ceramah.

\section{Hasil dan Pembahasan}

Hasil penelitian ini mencangkup hasil selama proses kegiatan belajar mengajar menggunakan model experiential learning berbantuan eksperimen di kelas X MIA 2 dan model pembelajaran konvensioanal menggunakan metode ceramah dan diskusi di kelas X MIA 1 di SMA Negeri 3 Palu yang meliputi hasil belajar kimia siswa.

\section{Analisis Instrumen}

Instrumen penelitian yang digunakan pada penelitian ini yaitu berupa penilaian proses belajar mengajar dan tes hasil belajar. Penilaian proses belajar mengajar menggunakan lembar observasi terhadap guru dan siswa, instrumen ini menilai tercapainya langkah-langkah model pembelajaran yang diterapkan pada masing - masing kelas selama proses belajar mengajar berlangsung.

Instrumen penelitian tes hasil belajar tersebut dianalisis menggunakan aplikasi anates $\mathrm{V} 4 \mathrm{Tujuan}$ menggunakan aplikasi anates $\mathrm{V} 4$ untuk mengetahui validitas, tingkat kesukaran tes, reliabilitas serta daya pembeda tiap butir soal instrumen. Hasil analisis instrumen penelitian setelah menggunakan anava tes adalah dari 40 soal yang dianalisis diperoleh 20 soal yang termasuk kategori valid dan 20 soal termasuk kategori tidak valid. Selanjutnya 20 soal tersebut digunakan untuk mengukur hasil belajar kimia siswa baik pada pretes dan postes pada materi larutan elektrolit dan nonelektrolit. Pretes bertujuan untuk mengetahui kemampuan awal yang dimiliki oleh siswa dan untuk menentukan kelas eksperimen dan kelas kontrol sedangkan postes bertujuan untuk mengetahui sejauh mana pengaruh model experiential learning berbantuan eksperimen pada materi larutan elektrolit dan nonelektrolit terhadap hasil belajar kimia siswa kelas X MIA di SMA 3 palu.

Data analisis perbandingan tes akhir belajar pada siswa kelas eksperimen dan kelas kontrol disajikan pada Tabel 1 .

Tabel 1. Perbandingan hasil belajar kimia siswa kelas eksperimen dan kelas kontrol

\begin{tabular}{ccc}
\multicolumn{2}{c}{ Tes akhir siswa } & (Postes) \\
uraian & Kelas eksperimen & Kelas kontrol \\
\hline Sampel & 32 & 32 \\
Nilai terendah & 41 & 28 \\
Nilai tertinggi & 86 & 80 \\
Skor rata-rata & 56.45 & 46.15 \\
Standar deviasi & 11.05 & 11.88 \\
Jumlah & 32 & 32 \\
\hline
\end{tabular}

Berdasarkan data hasil belajar kimia siswa pada Tabel 1 dapat dilihat bahwa nilai rata-rata kelas eksperimen dengan menggunakan model eksperiential learning berbantuan eksperimen lebih tinggi daripada nilai rata-rata kelas kontrol yang menggunakan model konvensional dengan metode ceramah dan diskusi.

\section{Analisis Data Hasil Belajar}

Analis data pada penelitian ini terdiri dari pengujian normalitas, pengujian homogenitas, dan pegujian hipotesis.

\section{Pengujian Normalitas}

Pengujian normalitas bertujuan untuk mengetahui apakah data yang diperoleh terdistribusi normal atau tidak berdasarkan tes hasil belajar kimia siswa pada uji normalitas untuk kelas eksperimen diperoleh $\chi_{\text {hitung }}^{2}=6.89$ dan $\chi_{\text {tabel }}^{2}=7.81$ dan normalitas untuk kelas kontrol adalah $\chi_{\text {hitung }}^{2}=$ 4.19 dan $\chi_{\text {tabel }}^{2}=5.99$. Hal ini membuktikan bahwa kedua kelas memenuhi kriteria data berdistribusi normal.

\section{Pengujian Hipotesis}

Hipotesis yang digunakan adalah uji parametrik yaitu uji-t satu pihak (kanan). Hal ini disebabkan karena data berdistribusi normal. Pengujian hipotesis ini bertujuan untu membedakan hasil belajar kimia menggunakan model eksperiential learning berbantuan eksperimen dengan model konvensional berbantuan metode ceramah dan diskusi. Kriteria pengujiannya adalah $\mathrm{H}_{\mathrm{o}}$ diterima jika Jika $\mathrm{t}_{\text {hitung }} \leq \mathrm{t}_{1}$ $\alpha$ dimana $t_{\text {tabel }}$ didapat dari daftar distribusi t dengan $\mathrm{dk}=\left(\mathrm{n}_{1}+\mathrm{n}_{2}-2\right)$ dan peluang $\left(\mathrm{t}_{1}-1 / 2 \alpha\right)$ dengan $\alpha=$ 0.05 dan untuk harga - harga t lainnya ditolak.

Berdasarkan hasil diperoleh $3.55>1.67$ berada pada daerah penolakan $\mathrm{H}_{0}$ sehingga $\mathrm{H}_{0}$ ditolak dan $\mathrm{H}_{1}$ diterima, artinya terdapat pengaruh model Experiential Learning berbantuan Eksperimen pada materi larutan elektrolit dan nonelektrolit terhadap hasil belajar siswa kimia Kelas X MIA SMA Negeri 3 Palu.

Model experiential learning adalah model pembelajaran melalui suatu pengalaman belajar (Siti, 2014). Pengalaman belajar ini melibatkan 
siswa secara aktif dalam kegiatan pembelajaran. Model pembelajaran ini menekankan pada proses pengkontruksian pengetahuan melalui transformasi pengalaman (Sharlanova, 2014).

Penelitian ini dilakukan untuk mengetahui adanya pengaruh model Experiential Learning berbantuan eksperimen pada materi larutan elektrolit dan nonelektrolit terhadap hasil belajar kimia siswa kelas X MIA SMA Negeri 3 Palu. Objek penelitian yang digunakan pada penelitian ini yaitu dua kelompok kelas, yaitu kelas X MIA 1 sebagai kelas kontrol dan kelas X MIA 2 sebagai kelas eksperimen. Pelaksanaan penelitian pada kelompok eksperimen dan kelompok kontrol menggunakan jumlah waktu pembelajaran yang sama, yaitu 6 jam pelajaran. Selain jumlah waktu pembelajaran yang sama, pokok materi yang disampaikan pada kelompok eksperimen dan kelompok kontrol juga sama yaitu larutan elektrolit dan nonelektrolit dengan urutan penyampaian materi yang sama pula. Perlakuan yang berbeda hanya pada model pembelajaran yang digunakan, di mana kelompok eksperimen menggunakan model Experiential Learning berbantuan eksperimen sedangkan kelompok kontrol menggunakan metode diskusi kelompok. Sumber data yang digunakan pada penelitian ini berasal dari tes hasil belajar siswa. Lembar observasi yang digunakan bertujuan untuk menilai pelaksanaan tahap-tahap model pembelajaran pada kelas eksperimen. Sedangkan tes hasil belajar siswa berupa soal pilihan ganda yang berjumlah 20 butir soal yang sudah tervalidasi yang diberikan sesudah pembelajaran (posttest).

Pelaksanaan penelitian ini dilakukan pada kelas X MIA 1 dan X MIA 2 dengan jumlah siswa sebanyak 64 siswa, yang terdiri dari 32 siswa kelas $X$ MIA 1 dan 32 siswa kelas X MIA 2. Sebelum melaksanakan kegiatan pembelajaran, kedua kelas diberikan tes awal (pre-test) dengan tujuan untuk mengetahui pengetahuan awal dari siswa, selain itu tes awal ini bertujuan untuk menentukan kelas eksperimen dan kelas kontrol. Berdasarkan hasil pretest yang diperoleh nilai rata-rata untuk kelas X MIA 1 sebesar 22.16 sedangkan nilai rata-rata untuk kelas X MIA 2 sebesar 19.08. Kelas dengan nilai rata-rata rendah akan dijadikan sebagai kelas eksperimen sedangkan kelas yang memiliki nilai rata-rata lebih tinggi akan dijadikan sebagai kelas kontrol. Sehingga kelas X MIA 1 dipilih menjadi kelas kontrol yang diberikan perlakuan model experiential learning berbantuan eksperimen sedangkan kelas X MIA 2 dipilih menjadi kelas kontrol yang diberikan perlakuan model pembelajaran konvensional dengan metode diskusi ceramah.

Hasil belajar siswa diukur dengan menggunakan instrumen tes tertulis yang telah divalidasi dan diberikan kepada siswa sebelum (pretest) dan sesudah (postest) diberikan pembelajaran (Khilmi, 2013). Hasil dari tes tertulis tersebut kemudian dianalisis menggunakan analisis statistik deskriptif dan analisis statistik inferensial untuk melihat bagaimana pengaruh model pembelajaran terhadap hasil belajarnya (Sugiyono, 2010).

Berdasarkan hasil penelitian yang diperoleh dari kedua kelas untuk analisis statistik deskriptif dengan menggunakan uji N-gain (Wulandari, 2013). Pengujian ini untuk menentukan hubungan nilai pretest dan postest kelas eksperimen dan kelas kontrol atau melihat peningkatan hasil belajar siswa berdasarkan data pretest dan postest diperoleh hasil dari kelas eksperimen dan kelas kontrol berturutturut: kategori rendah 8 dan 12 orang, kategori sedang 21 dan 19 orang, kategori tinggi 2 dan 1 orang. Hal ini menunjukkan $\mathrm{N}$-gain kelas eksperimen mengalami peningkatan yang lebih tinggi dari pada kelas kontrol. Perbedaan nilai Ngain dari kedua kelas disebabkan karena hasil belajar siswa tidak hanya dipengaruhi oleh model pembelajaran yang diterapkan tetapi juga faktor lain seperti kondisi fisik, bakat, minat, motivasi, suasana belajar, ekonomi keluarga, serta sarana dan prasarana (Yani, 2016).

Sedangkan untuk analisis inferensial dengan menggunakan uji-t satu pihak baik kelas eksperimen maupun kelas kontrol memiliki data yang berdistribusi normal dan varians yang homogen, serta analisis uji t- satu pihak (kanan) diperoleh thitung $\leq \mathrm{t} 1-\alpha$ dimana (thitung $=3.55$ dan ttabel $=$ 1.67) jelas berada pada daerah penolakan $\mathrm{H}_{0}$ sehingga $\mathrm{H}_{0}$ ditolak dan $\mathrm{H}_{\mathrm{a}}$ diterima, maka dapat dikatakan bahwa ada pengaruh model pembelajaran experiential learning berbantuan eksperimen terhadap hasil belajar siswa.

Berdasarkan data yang diperoleh baik pada uji statistik deskrptif maupun statistik inferensial model experiential learning berbantuan eksperimen memiliki pengaruh dengan hasil yang lebih tinggi terhadap hasil belajar siswa. Hal ini disebabkan karena dalam proses model experiential learning berbantuan eksperimen dihadapkan pada permasalahan nyata yang membangkitkan rasa keingintahuan untuk melakukan penyelidikan sehingga dapat meningkatkan keterampilanketerampilan berfikir, menumbuhkan inisistif siswa dalam bekerja sama, motivasi internal untuk belajar dan dapat ,mengembangkan hubungan dalam bekerja kelompok (Maratus dkk., 2016).

Kelebihan dari model experiential learning berbantuan eksperimen dibandingkan dengan pembelajaran konvensional adalah keaktifan siswa dalam membangun pengalaman belajar (Farooq, 2011). Pengalaman belajar ini dapat diperoleh dari kegiatan eksperimen. Experiential learning berbantuan eksperimen dapat melibatkan siswa untuk aktif berfikir dan menemukan secara langsung pengertian atau konsep yang ingin diketahuinya. Siswa menjadi lebih aktif serta mampu mengungkapkan ide dan gagasan mereka dengan baik (Sari \& Surya, 2017) selain dari kelebihan tersebut, adapula kekurangan dari model ini yaitu membutuhkan waktu yang cukup lama dalam bereksperimen untuk memperoleh kesimpulan atau suatu konsep yang utuh. 
Selama penelitian berlangsung ditemukan beberapa kendala. Diantaranya kendala pertama yaitu kurangnya siswa yang memiliki buku panduan. Usaha yang dilakukan peneliti yaitu dengan memberikan tugas kepada siswa berkaitan dengan materi yang akan dibahas. Kendalam kedua yaitu kemauan siswa untuk membaca suatu masalah masih kurang, sehingga jika dihadapkan dengan soal pemecahan masalah maka mereka akan langsung bertanya pada guru. Kendala ini dapat peneliti atasi dengan menyampaikan kepada siswa pentingnya memahami masalah untuk menyelesaikan soal tersebut, selain itu dengan memberikan soal yang menarik dan menantang siswa untuk membaca dan mengetahuinya. Kendala ketiga yaitu terdapat beberapa siswa yang kurang senang dengan pembagian kelompok yang telah ditetapkan. Usaha yang dilakukan peneliti adalah dengan memberikan pengertian atau memberi tahu alasan kenapa siswa dikelompokkan.

\section{Kesimpulan}

Dari data analisis yang menunjukkan $3.55>$ 1.67 berada pada daerah penolakan $\mathrm{H} 0$ sehingga $\mathrm{H} 0$ ditolak dan $\mathrm{H} 1$ diterima, dapat disimpulkan bahwa terdapat pengaruh model experiential learning berbantuan eksperimen pada materi larutan elektrolit dan non-elektrolit terhadap hasil belajar kimia siswa kelas X MIA SMA Negeri 3 Palu.

\section{Ucapan Terima kasih}

Ucapan terima kasih penulis sampaikan kepada Rismaida selaku guru kimia di SMAN 3 Palu, dan seluruh pihak yang telah membantu penulis dalam menyelesaikan penelitian ini.

\section{Referensi}

Aisha, Z., \& Nurhayati, S. (2013). Efektifitas classroom reflection assessment melalui cooperative learning dalam peningkatan hasil belajar. Chemistry in Education, 2(2), 178-184.

Arifin, Z. (2009). Evaluasi pembelajaran, prinsip, teknik, prosedur. Bandung: Remaja Rosdakarya.

Aunurrahman, (2009). Belajar dan pembelajarans. Bandung: Alfabeta.

Dewi, I., Kusmariyatni, N., \& Suartama, I. (2013). Pengaruh model pembelajaran kooperatif tipe MURDER terhadap prestasi belajar IPA siswa kelas IV di gugus II kecamatan Sidemen. Jurnal Mimbar PGSD Universitas Pendidikan Ganesha, 1(1), 1-10.

Fajri, L., Martini, K. S., \& Nugroho, A. (2012). Upaya peningkatan proses dan hasil belajar kimia materi koloid melalui pembelajaran kooperatif tipe TGT (teams games tournament) dilengkapi dengan teka-teki silang bagi siswa kelas XI IPA 4 SMA Negeri 2 Boyolali pada semester genap tahun ajaran 2011/2012. Jurnal Pendidikan Kimia (JPK), 1(1),89-96.
Farooq, (2011). Experiential learning from a constructivist perspective: reconceptualizing the kolbian cycle. International Journal of Learning \& Development, 1(2), 27-37.

Gonen, S., \& Ozek, N. (2005). Use J. bruner learning theory in physical experimental activity. Journal of Physics Teacher Education Online, 2(3).19-21.

Isjoni. (2009). Pembelajaran kooperatif meningkatkan kecerdasan komunikasi antar peserta didik. Yogyakarta: Pustaka Belajar.

Khilmi, M., \& Assabiqi. (2013). Peningkatan minat siswa melalui experiential learning dalam pembelajaran passing bawah bola voli studi pasa siswa kelas IV SDN Pusungmalang. Jurnal Pendidikan Olaraga dan Kesehatan Jasmani, 1(3), 648-651.

Kolb, A. Y., \& Kolb, D. A. (2005). Learning style and learning spaces: Enhancing experimental learning in higher education. Academy of Management Learning and Education, 4(2), 193-212.

Kunandar, (2007). Guru profesional implementasi kurikulum tingkat satuan pendidikan (KTSP). Jakarta: PT Raja Grafindo.

Maratus, S., Sholilah, M., Utaya, S., \& Susilo, S. (2016). Pengaruh model experiential learning terhadap kemampuan berpikir siswa sma. Jurnal Pendidikan: Teori, Penelitian dan Pengembangan, 1(11), 2096-2100.

Sagala, S. (2010). Konsep dan makna pembelajaran untuk membantu memecahkan problematika belajar dan mengajar. Bandung: Alfabeta.

Sari, A. (2012). Meningkatkan pemahaman konsep kimia melalui model pembelajaran inkuiri dengan menggunakan metode pictorial riddle pada materi struktur atom siswa kelas X SMA. Jurnal Pendidikan Kimia (JPK), 2(1).57-62.

Sari, M., \& Surya, E. (2017). Improving the learning outcomes of students using number head together model in the subjects of mathematics. International Journal of Sciences: Basic and Applied Research, 33(3), 311-319.

Sharlanova, V. (2004). Experiential learning. Tarkia Journal of Sciences, 2(4), 36-39.

Sugiyono. (2010). Statistika untuk penelitian. Bandung: Alfabeta.

Syaodih, N. (2010). Metode penelitian pendidikan. Bandung: PT Remaja Rosdakarya.

Uno, H. B. (2009). Model pembelajaran menciptakan proses belajar mengajar yang kreatif dan efektif. Jakarta: Bumi Aksara.

Lestari N. W. R., Sadia, I. W., \& Suma, K. (2014). Pengaruh model experiential learning terhadap keterampilan berpikir kritis dan motivasi berprestasi siswa. E-journal Program Pascasarjana Universitas Pendidikan Ganesha, 4(1), 156-163. 
Wulandari, A. D., Kurnia, \& Sunarya, Y. (2013). Pembelajaran praktikum berbasis inkuiri terbimbing untuk meningkatkan keterampilan berpikir kritis siswa SMA pada laju reaksi. Jurnal Riset dan Praktik Pendidikan Kimial(1), 18-26.
Yani, (2016). Pembelajaran berbasis pengalaman (experiental learning) untuk meningkatkan keterampilan berfikir kritis dan aktivitas mahasiswa. Jurnal STKIP NU Indramayu, 7(3), 148-152. 